\title{
Renewable Resource Management with Stock Externalities: Coastal Aquifers and Submarine Groundwater Discharge
}

\author{
Sittidaj Pongkijvorasin \\ Chulalongkorn University \\ James Roumasset \\ University of Hawaii at Manoa \\ Thomas Kaeo Duarte \\ Kamehameha Schools \\ and \\ Kimberly Burnett \\ University of Hawaii Economic Research Organization \\ Working Paper No. 08-08R ${ }^{1}$ \\ November 10, 2008
}

\begin{abstract}
This paper develops a hydrologic-ecologic-economic model of groundwater use. Particularly, we model coastal groundwater management and its effects on submarine groundwater discharge, nearshore marine water quality, and marine biota. We show that incorporating the external effects on nearshore resources increases the optimal sustainable steady-state head level. Numerical simulations are illustrated using data from the Kuki'o region on the island of Hawaii. Two different approaches for incorporating the nearshore resource are examined. Including algae's market value in the objective function results in only slightly lower rates of extraction. When a minimum constraint is placed on the stock of the keystone species, however, greater conservation may be indicated. The constraint also results in non-monotonic paths of water extraction, head level, and water price in the optimal solution.
\end{abstract}

Keywords: groundwater management, marine ecology, dynamic optimization, safe minimum standard, sustainability science.

JEL codes: Q25, Q28, C61, D62

\footnotetext{
${ }^{1}$ Revised version of WP 07-13, “Coastal Groundwater Management with Nearshore Resource Interactions.”
} 


\section{Introduction}

It has been long recognized in resource economics that the optimal harvest path of a resource depends on other amenity values or ecosystem services that the resource generates. For example, the optimal use of energy resources over time depends on their contribution to global warming. The fundamental theory of resource extraction in the presence of ecosystem services goes back at least to Pearce and Markandya (1989), who propose a unifying condition for the optimal extraction of a renewable or non-renewable resource, namely that the efficiency price of the resource equals the total marginal cost of using the resource, including extraction, user, and externality costs. Some ambiguities regarding the meaning of marginal user cost and marginal externality costs have limited the applicability of the theory, however.

The now canonical resource-externality problem is the case of global warming. Fossil fuel consumption contributes to an accumulation of greenhouse gases (GHG) in the atmosphere requiring a corrective tax or cap and trade scheme whereby users of petrochemicals face the shadow price of carbon and internalize the externality. In the context of global warming, the externality occurs as a result of the use of resource. Environmental damage is determined by the stock of the externality (the level of the stock of GHGs in the atmosphere), not the flow. In other cases, the externality is generated due to the stock of the resource, rather than its use. This problem has been largely overlooked in environmental economics. 2

Despite the relative dearth of literature about these resource-externality problems where the stock of the resource causes the externality and the stock of externality determines

2 See e.g. Barbier (1994) for an exception. 
the damage, these examples are common in the real world. This paper deals with one example - the interaction between the stock of groundwater and a nearshore marine ecosystem. A decrease in the stock of underground freshwater, caused by extraction, results in lower submarine groundwater discharge (SGD) ${ }^{3}$, which in turn effects the water quality in terms of, for example, salinity or nutrient load. The change in water quality will obviously influence the growth of some nearshore species. Our motivating problem in the present study is the effect that coastal-aquifer head levels have on groundwater discharge that, in turn, is an important determinant of marine ecosystems.

Groundwater has been modeled as renewable as well as a non-renewable resource. If recharge is exogenous and small relative to consumption, it can be simply subtracted from consumption and optimal extraction solved according to the theory of the mine, with respect to net demand. (Early examples include Renshaw, 1963: Burt, 1964; Brown and Deacon, 1972; and Gisser and Sanchez,1980.) On the other hand, if recharge is dependent on stock, then groundwater can be modeled as a renewable resource.

Another important feature of coastal aquifers is SGD. The discharge depends on the amount of groundwater stock; the higher the stock, the higher the discharge, due to the effects of aquifer water pressure and ground-ocean water interaction. This special characteristic requires a model that allows for endogenous net recharge. The coastal groundwater problem, then, is analogous to the prototypical renewable resource management where natural growth is a function of its own stock. Endogenous net recharge was introduced in earlier groundwater modeling, for example, by Tsur and Graham-Tomasi (1991). The existing endogenous recharge models of groundwater management, however, focus only on

3 Submarine groundwater discharge is any and all flow of water on continental margins from the seabed to the coastal ocean, regardless of fluid composition or driving force (Burnett et al. 2003). 
the effect of groundwater stock on the change in groundwater net recharge (i.e., the higher the groundwater stock, the more groundwater discharges into the ocean). To our knowledge, the external effects of groundwater discharge have not been discussed in the economic literature.

SGD impacts nearshore marine ecologies via changes in nutrient loads, temperature, and salinity (Johannes 1980, UNESCO 2004). These disturbances may significantly alter the coastal ecosystem, endangering unique plants and animal species with ecological, cultural, or economic value. In this paper, we are particularly interested in the effects of water quality on a Hawaiian indigenous marine algae (also called "limu" in Hawaiian), which is regarded as a keystone species of the nearshore ecosystem (Abbott 1978). This type of limu thrives where freshwater inputs are abundant. On the west coast of the island of Hawaii, nearly all the freshwater entering the ocean comes from SGD (Kay et al., 1977). An increase in salinity, caused by a decrease in freshwater discharge, may induce less growth of the native algae. It is important to note that the growth of algae also depends on other factors, e.g., nutrients. In this paper, we use salinity level as an indicator for water quality affecting algae. 4

A similar conclusion was reached by Hanshaw and Black (1980) for an area of the Yucatan Peninsula. Direct correlative evidence was observed between SGD and algal biomass production in a tropical coastal lagoon located on the Yucatan Peninsula (Herrerra Silveira, 1998) and in the coastal waters of Long Island NY (La Roche et al., 1997). While correlative evidence exists, manipulative studies investigating the relationship between SGD and the growth of a specific marine alga have not been examined in any previous literature.

4

Decreased salinity is directly correlated to increased amounts of high nutrient groundwater or surface water. As such, there exists a continuum from low salinity, high nutrient water to high salinity, low nutrient water. It is assumed that for each algal species there is an optimal range of nutrient and salinity conditions (among other biophysical variables). 
This research exemplifies an approach to sustainability science ${ }^{5}$, wherein the focal point of the research is the specific policy question or resource management. This paper illustrates a transdisciplinary approach to resource, environmental, economic, and social systems. Despite numerous exhortations to pursue sustainability science, there is a paucity of examples of transdisciplinary studies organized to deliver resource management and policy prescriptions. In this study, we are particularly interested in the policy of groundwater management in the presence of a stock externality.

In the next section, we provide a regional hydrologic-ecologic-economic model concerning the interaction between groundwater use and the nearshore ecosystem. Although the model is generalized so that it is applicable to any coastal aquifer system with valuable nearshore resources, particular interest is paid to the Hawaii's coastal ecosystem as a case study. This study also allows for the use of the higher cost seawater desalination to meet water demand. This is known as a "backstop" resource. Incorporating the possibility of using desalinated water either as a backstop resource or replenishment of an excessively depleted aquifer and the time paths of water extraction for different cases are analytically discussed. We show that when the value of limu is considered, the aquifer's head level must be maintained at a higher level than otherwise in the steady state. Desalinated water will be used only when the shadow price of water in the absence of desalination exceeds the cost of desalination.

Section 3 illustrates the model with a numerical example using data from the Kuki'o region on the north Kona Coast on the island of Hawaii. Two different approaches

\footnotetext{
${ }^{5}$ See e.g.Clark, W.C. 2007. Sustainability Science: A room of its own.
} 
incorporating the limu consideration are discussed. The first approach is to include the market value of limu in the model. This approach results in a groundwater extraction rate that is only slightly lower than when limu is not considered, since the market value of limu is relatively insignificant compared to the value of water. The other approach is to impose a "safe minimum standard" level for the limu stock as a constraint, leading to lower optimal extraction rates. The simulation shows non-monotonic paths of water extraction and head level in the optimal solution for this case. The conclusions are in section 4.

\section{The Model}

Let $p\left(x_{t}\right)$ represent the price of water, which depends on the total amount of water used $\left(x_{t}\right)$. At any time $t, q_{t}$ amount of water is extracted from the aquifer. The extraction cost increases when the head level is lower because the water must be pumped a farther distance and, in some cases, the water may become brackish and need to be desalinated. The marginal cost of water extraction is assumed to be a positive, decreasing, and convex function of the head level, i.e., $c(h) \geq 0, c^{\prime}(h)<0$, and $c^{\prime \prime}(h)>0$.

We assume that an abundant but expensive alternative freshwater source exists. For example, freshwater can be produced by seawater desalination. This is a special feature when dealing with coastal groundwater management, as seawater is abundant in the area. We denote $\bar{p}$ as the fixed cost of producing water from desalination, and $b_{t}$ is the amount of water produced by desalination technology at time $t$.

The change in the head level of the aquifer is explained by natural recharge $(R)$, amount of water extracted $(q)$, and the water discharge to the ocean $(l)$. The recharge is assumed to be constant; or in other words, the average rainfall is fixed over time. As the head level increases, water pressure and surface area from which water can leak increase. Thus, 
there is more water discharging from the aquifer into the ocean when the head level is high. We model discharge as a positive, increasing, convex function of head level, i.e., $l(h) \geq 0$, $l^{\prime}(h)>0$, and $l^{\prime \prime}(h)>0$. The state of the aquifer can be explained as: $\dot{h}_{t}=a\left[R-l\left(h_{t}\right)-q_{t}\right]$, where $a$ is a conversion factor converting volume to height. ${ }^{6}$

Assume that, at any time $t$, limu is harvested at rate $m_{t}$; and $p_{m}(m)$ is the price of limu, which depends on the amount of limu consumed. As the stock level decreases, it is more difficult to find and harvest the limu. The marginal cost of harvesting limu is assumed to be positive, decreasing, and convex with the stock of limu $(S)$, i.e., $c_{m}(S) \geq 0, c_{m}{ }^{\prime}(S)<0$, and $c_{m}{ }^{\prime \prime}(S)>0$. The natural growth of limu depends on the size of its own stock and water quality, $G(S, W)$. With respect to its own stock, growth is assumed to have the traditional properties; strictly concave and attaining a maximum at a finite value of $S$. Examples of water quality indicators, which may affect the growth of limu, are salinity, nitrogen, and temperature. These indicators are related to the amount of freshwater discharged, $W=W(l(h))$. From these relationships, the natural growth of limu can be expressed in terms of limu stock and head level, $g(S, h)$. Assume further that freshwater positively affects limu growth, $g_{h}(S, h)>0$. The change in limu stock over time is explained by: $\dot{S}=g(S, h)-m$.

In the first-best world, a social planner maximizes net social benefit by choosing the paths of groundwater extracted, desalinated water, and limu harvested. However, in the real world, controlling the amount of limu harvested may be politically and administratively difficult. We assume that the government does not have control over limu harvesting. Limu is considered an open access resource, which implies that it will be harvested until its price

$6 a$ is specific to the site. It depends on the shape (e.g. length and width), and the porosity of the aquifer. 
equals its extraction cost $p_{m}(m)=c_{m}(S)$. The social planner's problem is to choose the paths of groundwater extraction and desalinated water in order to maximize the social net benefit, which is equal to consumer surpluses, derived from water and limu consumption, minus the costs of obtaining the water and limu. Given discount rate $r$, the problem can be written as:

$$
\begin{aligned}
\max _{q_{t}, b_{t}} \int_{0}^{\infty} e^{-r t}\left[\int_{0}^{q_{t}+b_{t}} p(x) d x-c\left(h_{t}\right) q_{t}-\bar{p} b_{t}+\int_{0}^{m_{t}} p_{m}(y) d y-c_{m}\left(S_{t}\right) m_{t}\right] d t \\
\text { s.t. } \quad \dot{h}_{t}=a\left[R-l\left(h_{t}\right)-q_{t}\right] \\
\dot{S}_{t}=g\left(S_{t}, h_{t}\right)-m_{t}
\end{aligned}
$$

Suppressing time subscripts, the current-value Hamiltonian is:

$$
H=\int_{0}^{q+b} p(x) d x-c(h) q-\bar{p} b+\int_{0}^{m} p_{m}(y) d y-c_{m}(S) m+\lambda a[R-l(h)-q]+\theta[g(S, h)-m]
$$

where $\lambda \geq 0$ is the co-state variable of the groundwater stock, in terms of the head level, and $\theta \geq 0$ is the co-state variable of the limu stock. The corresponding first-order conditions are:

$$
\begin{array}{lll}
\frac{\partial H}{\partial q}=p(q+b)-c(h)-\lambda a \leq 0 & (=0 \text { if } q>0) & \text { for all } \mathrm{t} \\
\frac{\partial H}{\partial b}=p(q+b)-\bar{p} \leq 0 & (=0 \text { if } b>0) & \text { for all } \mathrm{t}
\end{array}
$$

$-\frac{\partial H}{\partial h}=c^{\prime}(h) q+\lambda a l^{\prime}(h)-\theta g_{h}(S, h)=\dot{\lambda}-r \lambda \quad$ for all $\mathrm{t}$

$-\frac{\partial H}{\partial S}=c_{m}{ }^{\prime}(S) m-\theta g_{S}(S, h)=\dot{\theta}-r \theta \quad$ for all $\mathrm{t}$

The transversality condition is given by:

$\lim _{t \rightarrow \infty} \lambda(t) h(t)=0$ 
Since $H_{q_{i} q_{i}}=p^{\prime}(x)<0$, and $H_{b_{i} b_{i}}=p^{\prime}(x)<0, H$ is maximized. Equations (2) to (5) express the optimal conditions of water and limu management. Equation (2) explains that, at the optimum, whenever groundwater is extracted, its marginal user cost (MUC) must be equal to royalty (price minus extraction cost). Equation (3) implies that the desalination technology will not be introduced when the price of water is lower than the cost of desalination. When desalinated water is used, the price of water is equal to the cost of desalination. Equation (4) can be rearranged as:

$r \lambda+\lambda a l^{\prime}(h)=\dot{\lambda}-c^{\prime}(h) q+\theta g_{h}(S, h)$

Equation (7) explains that the marginal cost of water conservation (the left-hand side) should be equal to the marginal benefit (the right-hand side). The cost of water conservation consists of the forgone interest from royalty and the monetary value of increased discharge if the water is not extracted. The marginal benefits of water conservation include the change in royalty, the decrease in extraction cost (the head level is higher), and the benefit of water conservation on limu growth. The equality between the marginal benefit and the marginal cost of water conservation must hold over time. Equation (5) has the same interpretation as equation (7), but in terms of limu conservation. The condition requires the equality between the marginal cost of limu conservation and the marginal benefit. ${ }^{7}$

Without desalination, the steady state head level can be obtained by solving the firstorder conditions given that $b=0, \dot{p}=0, \dot{h}=0(q=R-l(h))$, and $\dot{\theta}=0$. The optimal condition at the steady state can be written as:

7

In this case, the marginal benefit and marginal cost of limu conservation are not controlled by limu extraction directly. However, the groundwater extraction path should be such that this condition is satisfied. 


$$
p(q)=c(h)-\frac{a(R-l(h)) c^{\prime}(h)}{r+a l^{\prime}(h)}+\frac{a g_{h}(S, h) \theta}{r+a l^{\prime}(h)}
$$

Assuming that $g_{h h}(S, h) \leq 0$, the derivative of the right-hand side of (8) with respect to the head level is unambiguously negative (see appendix A). Since the derivative of the left-hand side is positive, the steady state head level that solves equation $(8), h^{*}$, is unique.

However, if desalination technology is available, it will be introduced when the water price is high enough (i.e., when the shadow price of water in the absence of desalination exceeds the cost of desalination). From equation (3), when desalination technology is used, water price will be constant and equal to $\bar{p}$. Substituting $\bar{p}$ for $p$ in equation (2) and solving with equations (4) and (5), the steady state condition when desalination is used can be derived as:

$\bar{p}=c(h)-\frac{a(R-l(h)) c^{\prime}(h)}{r+a l^{\prime}(h)}+\frac{a g_{h}(S, h) \theta}{r+a l^{\prime}(h)}$

Since the left-hand side of equation (9) is constant and the derivative with respect to $h$ of the right-hand side is negative (see appendix A), a head level solving equation (9) is unique (called $\left.h_{b}{ }^{*}\right)$. Thus, when desalination is being used, the head level will remain constant at its optimum, $h_{b} *$. The optimal groundwater extraction is equal to $q_{b} *=R-l\left(h_{b} *\right)$.

Proposition 1: The steady state head level is increasing with the value of the limu.

Proof: See appendix B.

Proposition 1 indicates that the steady state head level must be maintained at a higher level if demand for limu increases. For example, when there is no externality, the last terms on the right-hand side of equations (8) and (9) disappear $(\theta=0)$. Since the last terms are positive, $h^{*}$ and $h_{b} *$ that solve equations (8) and (9) are lower when there is no externality. 
The use of desalination technology depends on the demand for water and the extraction cost. If groundwater is available to satisfy demand without drawing the aquifer down to $h_{b}{ }^{*}$ (i.e., $h^{*}>h_{b}{ }^{*}$, or $\mathrm{p}^{*}<\bar{p}$ ), desalination will never be used. In that case, the head level will remain at $h^{*}$ in the steady state. On the other hand, if $h^{*}<h_{b} *$, desalination will be used at the steady state. The steady state head level will be at $h_{b}{ }^{*}$.

The optimal extraction and price paths can be derived by solving equations (2), (4), and (5). The condition for the optimal trajectories can be expressed as:

$$
p=c(h)+\frac{\dot{p}-a(R-l(h)) c^{\prime}(h)}{r+a l^{\prime}(h)}+\frac{a g_{h}(S, h) \theta}{r+a l^{\prime}(h)}
$$

The optimal condition in equation (10) requires the equality between the marginal benefit of water extraction and the marginal cost, which consists of the extraction cost and the MUC. The MUC is composed of the forgone benefit from the higher future price of water, the higher extraction cost in the future, and the external cost that aquifer depletion has on the growth of limu.

From the head level equation of motion and equation (10), we can construct phase diagrams explaining the dynamic paths of head level and water price in different cases (figure 1). The $\dot{h}=0$ locus implies $q=R-l(h)$. Because the discharge function is increasing and convex with the head level, and the price is decreasing with water used, the $\dot{h}=0$ locus is increasing with the head level. For the $\dot{p}=0$ locus, if the desalinated water is used in the steady state, the $\dot{p}=0$ locus is a vertical line at $h_{b} *$ If desalination is not used in the steady state, the $\dot{p}=0$ locus will have a negative slope (according to equation (8)).

\section{$<<$ Figure 1 here $>>$}


From figure 1, given initial head level $\left(h_{0}\right)$, there will be an optimal amount of extraction that will yield a monotonic optimal time path of head level and water price (and thus water extraction) for both cases. If the initial head level is higher than the steady state level and $h^{*}<h_{b} *$ (figure $1(\mathrm{a})$ ), the price rises (extraction decreases) until it reaches the desalination cost, then desalinated water will be produced. However, if $h^{*}>h_{b} *$ (figure $1(\mathrm{~b})$ ), the price of water rises (water extraction decreases) and reaches the steady state; desalination will not be used. The problem is more complicated if the initial head level is lower than steady state. In that case, if $p^{*}>\bar{p}$ and $h^{*}<h_{b} *$ (figure 1 (a)), desalination will be used from the beginning until the head level reaches the steady state $\left(h_{b} *\right)$. If, however, $h^{*}>h_{b} *$ and $p^{*}<\bar{p}$ (figure 1 (a)), then the desalinated water will be used in the beginning. Desalination will cease when the price of water is lower than desalination cost. In this case, desalination will be used only in the beginning period (so called "frontstop").

\section{Application}

In this section, we provide a numerical example of the groundwater management model considering nearshore externalities. We have chosen the Kuki'o region, located along the North Kona coast of the island of Hawaii as a study site. This site is representative of the west coast of Hawaii Island and of many other water management units on similar volcanic islands.

\subsection{Data}


The Kuki'o aquifer is a thin basal or Ghyben-Herzberg lens (Duarte 2002). For the "one-dimensional, sharp-interface" case, the aquifer is modeled as a lens of less-dense freshwater floating on an underlying heavier saltwater. The state equation of head level can be expressed by: $\dot{h}_{t}=(2000 / 41 \theta W L)\left(R-l_{t}-q_{t}\right)$, where $\theta$ is the porosity; $W$ is the aquifer width; and $L$ is the aquifer length. ${ }^{8}$ In order to focus on the long-run optimal extraction path, we abstract from three-dimensional issues wherein cones of depression and disequilibrium spatial relationships are allowed in the short run. We also abstract from the brackish, transition zone separating fresh and salt water aquifer zones because the high porosity renders the Kuki'o transition zone relatively thin (Duarte, 2002).

For the Kuki'o aquifer, the porosity is 0.3 ; the aquifer unit width is $6000 \mathrm{~m}$.; and the aquifer length is $6850 \mathrm{~m}$. The state equation for the Kuki'o aquifer can be written as $\dot{h}_{t}=0.00000396\left(R-l_{t}-q_{t}\right)$. The water (e.g., recharge, discharge, or extraction) and head level are presented in units of "thousand cubic meters per year" ( $\left.\mathrm{tm}^{3} / \mathrm{y}\right)$ and "meters" (m) respectively.

Mink (1980) derives the structural expression for discharge as a function of the head level, assuming a sharp interface between fresh and saltwater. He shows that the relationship can be expressed by: $l(h)=k h^{2}$, where $k$ is a coefficient specific to an aquifer. Based on the average net recharge for the Kuki'o aquifer $\left(15,114 \mathrm{tm}^{3} / \mathrm{y}\right)$, the discharge function can be estimated as: $l(h)=4800 h^{2}$.

The costs of extracting groundwater are primarily due to the cost of energy needed to lift water to the ground level. Duarte (2002) estimates the unit cost of water extraction for the

\footnotetext{
${ }^{8}$ Mink (1980), p. 68.
} 
Kuki'o aquifer as a function of head level: $c=0.00083(403.2-h)$. Pitafi (2004), using 2001 data, estimates the unit cost of desalination and transportation of the desalted water to the existing water distribution system at $\$ 7$ per thousand gallons. Adjusted for inflation (Department of Business, Economic Development, and Tourism, 2006), we estimate the cost of desalination to be $\$ 7.7$ per thousand gallons in 2005 dollars $\left(\$ 2 / \mathrm{m}^{3}\right)$.

We model the demand for water with a linear demand function: $p_{t}=a-b q_{t}$. The Public Utility Commission price (retail price) for water in the region is $\$ 1.27 / \mathrm{m}^{3}$ ( $\$ 4.80$ / 1000 gallons). We assume that the price elasticity of water demand is -0.7 (based on Griffin, 2006 and Dalhuisen et al., 2003). The demand for water can be estimated as: $p_{t}=3.1-$ $0.00048 q_{t}$ accordingly.

At the current level of discharge, the average coastal seawater's salinity around the area is approximately $31 \mathrm{ppt}$ (parts per thousand) (Duarte 2002). We assume that if there is no discharge, the salinity level will be at the average level of seawater (36 ppt). Assuming that salinity is linearly related to discharge, the relationship can be expressed as: $s a l=36-$ $0.00033 l$

In this paper, we choose "limu kohu" (Asparagopsis taxiformisas) as the species of interest. Limu kohu is found along the west coast of Hawaii Island, and has the highest market value among all limu. According to the Department of Land and Natural Resources (2001), around 1,060 kg of limu kohu were commercially picked in the State of Hawaii (all islands), with a total value of $\$ 19,291$. The price of limu kohu is approximately $\$ 18.2 / \mathrm{kg}$. The same report shows that $15.3 \%$ of sea landing (all species) comes from the island of Hawaii and that out of that amount, 9.5\% comes from the area between Keahole to Kawaihae, which is our region of interest. Applying these ratios to the limu harvest, we infer that 15.4 
$\mathrm{kg}$ of limu kohu were harvested from this area in $2001 .^{9}$ Assuming that the elasticity of demand for limu is $-0.4,{ }^{10}$ the linear demand function for limu kohu in the area is, then, expressed by: $p_{m}=63.63-2.95 \mathrm{~m}$.

Due to the lack of data on the stock of limu, we assume that the initial limu stock is $100 \mathrm{~kg}$. The natural growth function of limu is assumed to be logistic, where natural growth depends on the net proportional growth rate $(\alpha)$ and the carrying capacity level $(S c c)$, i.e., $g=\alpha(1-S / S c c) S$. We assume that the carrying capacity of limu depends directly on the salinity level ${ }^{11}$ and can be explained by $S c c=200(31 /$ sal $)$. Studies by Hoyle (1976) and Wong and Chang (2000) indicate that the growth rates of limu approximately decrease by $28 \%$ when salinity increases from $31 \mathrm{ppt}$ (salinity at status quo) to $36 \mathrm{ppt}$ (ocean salinity with no discharge). Assuming that the growth rate is linearly related to salinity, we can write a function explaining the annual increase in limu as: $g=(0.8412-0.0172 s a l)(1-S / S c c) S{ }^{12}$

Data on the cost of harvesting limu is not explicitly available. As mentioned in an earlier section, the cost of limu harvest is assumed to relate adversely to the stock of limu, i.e., if the limu is abundant, the cost of harvesting will be lower. By assuming that the existing

9

The actual number of limu harvest maybe different due to two factors. First, because limu is not commercially harvested extensively in the area, the actual number may be lower. This is because the proportion data used here represents an all-species harvest, not only limu. Second, including the non-commercial harvest, the actual total harvest must be higher than the commercial harvest alone. With limited data, we assume here that the total harvest is equal to $15.4 \mathrm{~kg} /$ year. 10

Marasco (1974) reviews the elasticity of demand for fish in the U.S. He finds that it ranges from -0.65 to 0.23 .

11 The carrying capacity concept applied here can represent the competitiveness among different species. When salinity is high, invasive algae can grow better than indigenous algae. Thus, the carrying capacity of the indigenous specie decreases as salinity increases. This effect is separated from the direct effect of salinity on the growth rate. 12

Changes in limu growth can be explained by two factors: the direct effect of salinity on intrinsic growth rate, and the indirect effects from the change in carrying capacity (limu is crowded out by other competing species). 
condition is at the equilibrium, this implies that given the stock of limu stock is $100 \mathrm{~kg}$, and fishermen spend 2.5 hours to harvest $1 \mathrm{~kg}$ of limu. Given the minimum wage rate of $\$ 7.25 /$ hour, the unit cost of harvesting limu is $\$ 18.2 / \mathrm{kg}$ (which is equal to the price of limu according to the open-access's zero-profit condition). In order to numerically illustrate the model, we make further assumptions about the harvest cost. We assume that if limu is abundant, harvesting $1 \mathrm{~kg}$ of limu requires 0.5 hour. And if the stock of limu in the area is $200 \mathrm{~kg}$, fishermen require 1.5 hours to harvest $1 \mathrm{~kg}$ of limu. According to the above assumptions, the unit cost of harvesting limu can be expressed by $c_{m}=\left(0.5+\frac{200}{S}\right) 7.25$.

The parameters and functions used are presented in Table 1 and Table 2 respectively.

$<$ Table 1 here $>>$

<<Table 2 here > 


\subsection{Scenario Description}

Using the above data, we can calculate the optimal water extraction rates, price paths, head levels, and other variables of interest for different scenarios. We use Excel's Solver to solve the optimization problems. We begin with solving for optimal water management without the limu consideration (Baseline, B). The optimal water extraction rates, accounting for the market value of limu, are then derived (Limu, L). It is important to note that the value of limu in this calculation represents only its market value, ignoring any ecological and/or cultural value. Realizing that the consumption value of limu may not adequately capture its importance, we alternatively model the limu concern by imposing a minimum constraint on the level of limu stock. Particularly, the stock of limu is restricted such that it cannot be depleted by more than a certain percent of the current level. The minimum stock constraint can also be thought of as a "safe minimum standard" corresponding to the precautionary principle. The precautionary principle is commonly suggested by ecologists and environmental economists as a principle dealing with the problem of species loss, which involves ecological complexity and irreversibility (Harris 2005, p.147). For example, Gollier, Jullien, and Treich (2000) show that the higher scientific uncertainty about future risk is, the higher prevention society should take. ${ }^{13}$ In this paper, we run simulations with three different levels of constraint on the minimum allowable stock of limu --50\% (L50), 75\% (L75), and $90 \%$ (L90) of the current level.

\subsection{Results}

13

Mathematically, they show that the precautionary principle (as defined by previous prevention effort) is an optimal policy if the inverse of marginal utility is concave. 
For most scenarios, we present optimization results for 100 years ${ }^{14}$. However, due to the increase in the number of constraints and the limitation of the optimization software, the results of the L90 scenario are shown for 80 years.

Optimal water management without accounting for the value of limu (baseline scenario B) involves high groundwater extraction rates. The extraction rate starts from $5,763,670 \mathrm{~m}^{3} / \mathrm{y}$ and decreases very slowly eventually to $5,763,060 \mathrm{~m}^{3} / \mathrm{y} 100$ years later. The price increases very slightly from $\$ 333.40$ to $\$ 333.70$ per $\mathrm{tm}^{3}$. Because the price is always lower than the cost of desalination, desalination will never be used. The steady state head level in the optimal scheme is $1.40 \mathrm{~m}$ and will be reached in 65 years. The salinity level increases to $32.91 \mathrm{ppt}$, while the stock of limu decreases considerably from $100 \mathrm{~kg}$ to $46 \mathrm{~kg}$ in 100 years.

\subsubsection{With limu value}

When the value of limu is included (scenario "L"), optimal water extraction rates are lower, but only very slightly so. In this case, the extraction rate starts from 5,763,640 $\mathrm{m}^{3} / \mathrm{y}$ and decreases to $5,763,040 \mathrm{~m}^{3} / \mathrm{y}$ in 100 years. The steady state head and salinity level, however, are the same as in the previous case. The stock of limu is equal to $46 \mathrm{~kg}$ after 100 years. With the lower extraction rate, the price of water is slightly higher that of the case without limu. This is because the value of limu is relatively small compared to the benefit of water consumption. However, it must be emphasized that the value of limu in this example

\footnotetext{
14

Because the numerical example is illustrated by using a finite time simulation, we encounter the problem of extensive resource exploitation near the end period. In order to avoid this problem, we run the model with various lengths in order to confirm that each scenario reaches its steady state. We find that the steady state is reached within 100 years in all scenarios. In most cases, the model is run for 200 years. The results from first 100 years are reported.
} 
presents only the consumption value and ignores the other values it may have (e.g., ecological or cultural value).

These results indicate that desalination will not be used in any scenario. As mentioned in the theoretical section, this will be true if the desalination cost is more expensive than the steady state water price. In this simulation, groundwater alone is enough to satisfy demand with a sufficiently low extraction cost. Since the price of water is always lower than the desalination cost, desalination technology will never be implemented.

\subsubsection{With safe minimum constraints on the limu stock}

Imposing hard constraints on the level of limu stock leads to more conservative water management. Given that the stock of limu cannot be depleted by more than $50 \%$ (L50), the steady state head level is at $1.50 \mathrm{~m}$ (compared to $1.40 \mathrm{~m}$ from the no constraint case). The steady state extraction rate is approximately $4,380,480 \mathrm{~m}^{3} / \mathrm{y}$. The price of water starts from $\$ 0.35$ and reaches $\$ 1.00$ per $\mathrm{m}^{3}$ in the steady state.

If the limu stock has to remain at not less than $75 \%$ of the current level (L75), the steady state head level becomes $1.65 \mathrm{~m}$, with the steady state extraction rate around 2 million

$\mathrm{m}^{3} / \mathrm{y}$. In this scenario, since the groundwater extraction is low, it is optimal to use desalinated water. Desalination will be first introduced in year 38, when the price of water is equal to desalination cost, $\$ 2 / \mathrm{m}^{3}$. In the steady state, approximately $292,000 \mathrm{~m}^{3} / \mathrm{y}$ of desalinated water will be used.

If the limu stock has to be at least $90 \%$ of the current level (L90), the steady state head level is $1.71 \mathrm{~m}$. The steady state extraction rate is approximately 1.06 million $\mathrm{m}^{3} / \mathrm{y}$, while steady state desalination is around 1.23 million $\mathrm{m}^{3} / \mathrm{y}$ for this scenario (and desalination 
will begin after 17 years). Figures 2 to 6 show the time paths of head level, extraction rate, desalination rate, water price, and limu stock for each scenario.

<<Figure 2 here $>>$

$<<$ Figure 3 here $>>$

$<<$ Figure 4 here $>>$

$<<$ Figure 5 here $>>$

$<<$ Figure 6 here $>>$

It is interesting that time paths of the head level, groundwater extraction, desalination, and price can be non-monotonic. With the limu constraint, it is optimal to deplete the aquifer until the head level is lower than the steady state and then conserve water in the future to fill the aquifer until it reaches steady state. Imposing a limu constraint may also induce the use of desalination technology as an alternative backstop water source (e.g., in the L75 and L90 cases). In the L75 and L90 cases, it is optimal to stop using groundwater for some number of periods. The main results (steady states) from all scenarios are summarized in table 3 .

$<$ Table 3 here $>$

\section{Conclusions}


This paper provides a regional hydrologic-ecologic-economic model concerning the interaction between groundwater use and a nearshore ecosystem. We model coastal groundwater management allowing for endogenous net recharge (because of submarine groundwater discharge) and an alternative (abundant but expensive) water source (e.g., desalination). The effects of the discharge on the nearshore ecosystem, specifically on the nearshore valuable seaweed, are incorporated. To achieve efficiency, water must be extracted such that its price equals extraction plus user cost. The externality cost is included in the user cost since the externality is determined by the resource stock, not resource extraction. We show four possible patterns of optimal water use. It is also possible that the desalination technology will be introduced in the first period. Considering the effect on limu, the aquifer's steady state head level must be maintained at a higher level than otherwise. Desalinated water will be used only when the shadow price of water in the absence of desalination exceeds the cost of desalination.

We numerically illustrate the model using the data from Kuki'o, located on the North Kona Coast of the island of Hawaii. In the simulation, two different approaches are applied in order to incorporate the value of freshwater submarine groundwater discharge to the nearshore marine ecology. The first approach is to include the market value of limu directly in the objective function. In this case, the water extraction rate is slightly lower than when the value of limu is not included. This is because the value of limu is relatively insignificant compared to the high value of water. However, it should be emphasized that the value of limu in this scenario accounts only for the market consumption value and ignores the other potentially important values, such as cultural or ecological values. Desalination technology will never be 
used because groundwater is enough to satisfy the demand. The aquifer is optimally "overdrafted" during a first drawdown phase and then stabilized at a sustainable steady state.

The second approach, following the precautionary principle and "safe minimum standard," imposes a minimum stock constraint. We find an interesting result that the paths of water extraction, head level, and water price (without desalination) are non-monotonic. It is optimal to deplete the aquifer below the steady state level, followed by a conservation period wherein the aquifer head is increased up to the sustainable steady-state level.

Although the model in this paper is developed based on a groundwater-seaweed framework, it is applicable to other cases that share similar structures, for example, mangrove-nearshore fishery, or forest-wildlife models. In future work, the model can be extended in many ways. For example, in reality, the unit extraction cost may depend not only on the head level, but also on the extraction rate (i.e., via the effects from the cone of depression). Taking into account the presence of the cone of depression will make the model more realistic and thus provide more insight into the actual management problem. One of the most interesting extensions is to model the competition among nearshore species. The growth of limu does not depend solely on the water qualities, but also on the growth of other species, especially fish or invasive limu (e.g., Acanthophora spicifera). Another possible extension is to allow for control on limu harvesting. The comparison between open-access and optimal harvest of limu may provide useful insights.

The analysis in this paper is based on a short-run model, e.g., assuming that the wells already exist. The long-run problem of water allocation should involve the location, size and time of well-development. In this paper, we focus only on the first-best solutions. There may be some other constraints that should be taken into account. For example, for administrative 
purposes or given capacity of water pump limitations, water managers might want to require a constant water extraction rate over some periods in practice. Geographical constraints (e.g., land subsidence) are another important issue to consider. 


\section{Appendix A.}

Given that $c^{\prime}(h)<0, c^{\prime \prime}(h)>0, R-l(h)>0, l^{\prime}(h)>0$, and $l^{\prime \prime}(h)>0$, the derivative of the left-hand side of equations (7) and (8) with respect to $h$ is equal to

$c^{\prime}(h)+\frac{a c^{\prime}(h) l^{\prime}(h)}{r+a l^{\prime}(h)}+\frac{a(R-l(h)) c^{\prime \prime}(h)}{r+a l^{\prime}(h)}+\frac{a^{2}(R-l(h)) c^{\prime}(h) l^{\prime \prime}(h)}{\left(r+a l^{\prime}(h)\right)^{2}}$, which is unambiguously negative. 


\section{Appendix B: Comparative static analysis of the steady state head level with respect to}

\section{limu value}

If desalination is not used, the steady state head level is specified by equation (17), which can be expressed by:

$$
0=c\left(h^{*}\right)-\frac{a\left(R-l\left(h^{*}\right)\right) c^{\prime}\left(h^{*}\right)}{r+a l^{\prime}\left(h^{*}\right)}+\frac{a g_{h}\left(S, h^{*}\right) \theta}{r+a l^{\prime}\left(h^{*}\right)}-p(q)
$$

The derivative of $A$ with respect to $h$ is equal to

$$
\begin{aligned}
A_{h^{*}}= & c^{\prime}\left(h^{*}\right)+\frac{a c^{\prime}\left(h^{*}\right) l^{\prime}\left(h^{*}\right)}{r+a l^{\prime}\left(h^{*}\right)}+\frac{a\left(R-l\left(h^{*}\right)\right) c^{\prime \prime}\left(h^{*}\right)}{r+a l^{\prime}\left(h^{*}\right)}+\frac{a^{2}\left(R-l\left(h^{*}\right)\right) c^{\prime}\left(h^{*}\right) l^{\prime \prime}\left(h^{*}\right)}{\left(r+a l^{\prime}\left(h^{*}\right)\right)^{2}}+\frac{a g_{h h}\left(S, h^{*}\right) \theta}{r+a l^{\prime}\left(h^{*}\right)} \\
& -\frac{a g_{h}\left(S, h^{*}\right) \theta\left(r+a l^{\prime \prime}\left(h^{*}\right)\right)}{\left(r+a l^{\prime}\left(h^{*}\right)\right)^{2}}-p^{\prime}(q) \frac{\partial q}{\partial h^{*}}
\end{aligned}
$$

Given that $g_{h h}(S, h) \leq 0, A_{h^{*}}$ is unambiguously negative. The derivative of $A$ with respect to $\theta$ is equal to $A_{\theta}=\frac{a g_{h}\left(S, h^{*}\right)}{r+a l^{\prime}\left(h^{*}\right)}>0$

From the implicit function rule, it is easy to see that $\frac{\partial h^{*}}{\partial \theta}=-\frac{A_{\theta}}{A_{h^{*}}}>0$.

If desalination is used in the steady state, the steady state head level is specified by equation (18):

$$
0=c\left(h^{*}\right)-\frac{a\left(R-l\left(h^{*}\right)\right) c^{\prime}\left(h^{*}\right)}{r+a l^{\prime}\left(h^{*}\right)}+\frac{a g_{h}\left(S, h^{*}\right) \theta}{r+a l^{\prime}\left(h^{*}\right)}-\bar{p}
$$

The derivative of $B$ with respect to $h$ is equal to 


$$
\begin{aligned}
B_{h^{*}}= & c^{\prime}\left(h^{*}\right)+\frac{a c^{\prime}\left(h^{*}\right) l^{\prime}\left(h^{*}\right)}{r+a l^{\prime}\left(h^{*}\right)}+\frac{a\left(R-l\left(h^{*}\right)\right) c^{\prime \prime}\left(h^{*}\right)}{r+a l^{\prime}\left(h^{*}\right)}+\frac{a^{2}\left(R-l\left(h^{*}\right)\right) c^{\prime}\left(h^{*}\right) l^{\prime \prime}\left(h^{*}\right)}{\left(r+a l^{\prime}\left(h^{*}\right)\right)^{2}}+\frac{a g_{h h}\left(S, h^{*}\right) \theta}{r+a l^{\prime}\left(h^{*}\right)} \\
& -\frac{a g_{h}\left(S, h^{*}\right) \theta\left(r+a l^{\prime \prime}\left(h^{*}\right)\right)}{\left(r+a l^{\prime}\left(h^{*}\right)\right)^{2}}<0
\end{aligned}
$$

The derivative of $B$ with respect to $\theta$ is equal to

$$
B_{\theta}=\frac{a g_{h}\left(S, h^{*}\right)}{r+a l^{\prime}\left(h^{*}\right)}>0
$$

Like the previous case, the comparative static of the steady state head level with respect to

limu value is positive, i.e., $\frac{\partial h^{*}}{\partial \theta}=-\frac{B_{\theta}}{B_{h^{*}}}>0$. In either case (either desalination is used or not), the steady state head level is increasing with the value of limu. 


\section{References}

Abbott, I.A. 1978. The use of seaweed as food in Hawaii. Economic Botany 32: 409-412.

Barbier, E. B. 1994. Valuing Environmental Functions: Tropical Wetlands. Land Economics 70(2): 155-173.

Brown, G., and R. Deacon. 1972. Economic Optimization of a Single-Cell Aquifer. Water Resources Research 8: 557-564.

Burnett, W.C., H. Bokuniewicz, M. Huettel, W.S. Moore, and M. Taniguchi. 2003. Groundwater and porewater inputs to the coastal zone. Biogeochemistry 66: 3-33.

Burt, O.R. 1964. Optimal Resource Use over Time with an Application to Ground Water. Management Sciences 11: 80-93.

Clark, W.C. 2007. Sustainability Science: A room of its own. Proceedings of the National Academy of Science 104: 1737-1738; published online on February 6, 2007, 10.1073/pnas.0611291104.

Dalhuisen, J.M., R.J.G.M. Florax, H.L.P. de Groot, and P. Nijkamp. 2003. Price and income elasticities of residential water demand: a meta-analysis. Land Economics 79(2): 292308.

Department of Business, Economic Development, and Tourism. 2006. 2005 State of Hawaii Data Book. http://www.hawaii.gov/dbedt/info/economic/databook/db2005/.

Department of Land and Natural Resources. 2001. Commercial marine landings summary trend report: calendar year 2001. http://www.hawaii.gov/dlnr/dar/pubs/cmlstr2001.pdf. 
Duarte, Thomas Ka'eo. 2002. Long-term management and discounting of groundwater resources with a case study of Kuki'o, Hawaii. PhD diss., Massachusetts Institute of Technology.

Gisser, Micha. 1983. Groundwater: Focusing on the Real Issue. The Journal of Political Economy. 91(6): 1001-1027.

Gisser, M., and D.A. Sanchez. 1980. Competition versus Optimal Control in Groundwater Pumping. Water Resources Research 16: 638-642.

Gollier, Christian, Bruno Jullien, and Nicolas Treich. 2000. Scientific progress and irreversibility: an economic interpretation of the 'Precautionary Principle.' Journal of Public Economics 75: 229-253.

Griffin, Ronald C. 2006.Water resource economics: the analysis of scarcity, policies, and projects. Massachusetts: The MIT Press.

Hanshaw, B.B. and W. Back. 1980. Chemical Mass-wasting of the Northern Yucatan Peninsula by Groundwater Dissolution. Geology 8: 222-224.

Harris, Jonathan M. 2005. Environmental and natural resource economics: A contemporary approach. $2^{\text {nd }}$ ed. New York: Houghton Mifflin Company.

Herrera-Silveira, J. 1998. Nutrient-phytoplankton production relationships in a groundwaterinfluenced tropical coastal lagoon. Aquat. Ecocsyst. Health Manag. 1: 373-385.

Hoyle, Mitchell Dan. 1976. Autecology of ogo (Gracilaria bursapastoris) and limu manauea (G. coronopifolia) in Hawaii with special emphasis on Gracilaria species as indicators of sewage pollution. Ph.D. diss. University of Hawaii.

Johannes, R.E. 1980. The Ecological Significance of the Submarine Discharge of Groundwater. Marine Ecology 3: 365-373. 
Kay, A. E., L. S. Lau, E. D. Stroup, S. J. Doller, D. P. Fellows, and R. H. F.Young. 1977 Hydrological and ecological inventories of the coastal waters of West Hawaii, Univ. Hawaii, Water Resour. Res. Center Technical Report 105: 94 pp.

LaRoche, J., Nuzzi, R., Waters, R., Wyman, K., Falkowski, P.G., Wallace, D.W.R., 1997. Brown tide blooms in Long Island's coastal waters linked to interannual variability in groundwater flow. Glob. Change Biol. 3: 397-410.

Marasco, Richard. 1974. Food from the Sea: An Economic Perspective of the Seafood Market. American Journal of Agricultural Economics 56(5): 1030-37.

Mink, J. 1980. State of the groundwater resources of southern Oahu. Honolulu: Board of Water Supply.

Pearce, David, and Anil Markandya. 1989. Marginal opportunity cost as a planning concept. In Environmental Management and Economic Development. eds. Gunter Schramm and Jeremy J. Warford. Baltimore: The Johns Hopkins University Press.

Pitafi, Basharat A.K. 2004. Water resources, efficiency pricing, and revenue recycling. $\mathrm{PhD}$ diss., University of Hawaii.

Renshaw, E. F., 1963, “The management of ground water reservoirs," Journal of Farm Economics 45(2), 285-295.

Tsur, Y., and T. Graham-Tomasi. 1991. The Buffer Value of Groundwater with Stochastic Surface Water Supplies. Journal of Environmental Economics and Management 21: 201-224.

UNESCO. 2004. Submarine Groundwater Discharge: Management implications, measurements and effects, IHP-VI Series on Groundwater No.5, IOC Manuals and Guides No.44. 
Wong, S.L., and J. Chang. 2000. Salinity and light effects on growth, photosynthesis, and respiration of Grateloupia filicina (Rhodophyta). Aquaculture 182: 387-395. 